\title{
Michel FROMAGET, De l'enfer introuvable à l'immortalité retrouvée. Les fins dernières selon le christianisme originel
}

Paris, L'Harmattan, coll. « Cahiers Disputatio », 2017, 363 p.

\section{Daniel Vidal}



Ce document a été généré automatiquement le 12 janvier 2022.

(c) Archives de sciences sociales des religions 


\section{Michel FROMAGET, De l'enfer introuvable à l'immortalité retrouvée. Les fins dernières selon le christianisme originel}

Paris, L'Harmattan, coll. « Cahiers Disputatio », 2017, 363 p.

Daniel Vidal

\section{RÉFÉRENCE}

Michel FROMAGET, De l'enfer introuvable à l'immortalité retrouvée. Les fins dernières selon le christianisme originel, Paris, L'Harmattan, coll. «Cahiers Disputatio », 2017, $363 \mathrm{p}$.

Saint Thomas d'Aquin avait écrit, en une formule qui aurait pu être définitive, que Dieu n'avait pas, et ne saurait avoir, par principe, «idée du mal ». C'était laver Dieu de toute intervention dans la genèse et l'accomplissement de cela même qui relevait, également par principe, de l'homme, cet être seul responsable de son "péché », et de ce qui s'ensuit de ténèbres. Mais à bien consulter les évangélistes et les apôtres, et les Pères de l'Église qui en prolongeaient l'enseignement, et les confronter aux Docteurs qui fondèrent la Tradition de l'institution, ses dogmes, ses crédos et ses admonestations, Michel Fromaget, à partir de cette pensée radicale, met en cause le fondement même de cette Tradition: la notion d'enfer éternel, et d'immortalité nécessaire de l'âme. Bien entendu, cette terminologie, et tout l'univers sémantique qu'elle légitime, appartiennent à un domaine où les sciences sociales ne peuvent entrer immédiatement, tant étroite en est la porte. Mais de l'homme comme responsable de soi, et de son inscription au monde, s'il en est bien ici question, alors il peut en être dit la raison. Au demeurant, l'auteur en plusieurs endroits se réclame d'un droit de regard anthropologique. Ce qui invite à pousser en effet plus à fond la méditation et l'analyse 
qu'il nous propose, fondées sur une lecture des textes de l'Écriture et de ses premiers commentateurs, où chaque terme est pris dans sa littéralité et saisi dans sa contextualité, que M. Fromaget estime rigoureuses.

Ainsi des fins dernières, et de leur accomplissement. Traitant de la mort, le philosophe Schleiermacher écrivait qu'elle est une "trouée » à travers laquelle l'homme regarde l'infini. D'emblée, la question se pose alors du rapport entre ce regard vers l'infini, cette éternité revendiquée, et ce qu'il en va de la mort de l'homme - de l'éternité d'enfer que le catéchisme tridentin lui assigne, en tant que pécheur, ou de la vie éternelle qu'elle lui promet, s'il se reconnaît en Dieu. Un long parcours dans les deux Testaments, et les écrits patristiques, en quête de toute notation d'éternité, d'enfer, de damnation, etc., permet à l'Auteur de s'insurger contre les dogmes de la Tradition, qui disent l'enfer comme éternité de souffrances, et la vie éternelle comme un infini prédéterminé de grâces. De même que Thomas d'Aquin exonérait Dieu de toute idée du mal, Fromaget l'exonère de toute idée d'enfer. L'un ne va pas sans l'autre. "Dieu ignore l'enfer ». Bien entendu, il ne s'agit pas seulement de prendre l'enfer, ses feux et ses affres, en un sens évidemment métaphorique, mais d'en finir avec l'idée même d'enfer au-delà de la mort. "L'enfer éternel est proprement impensable ", écrit Fromaget, qui note que, dans le christianisme originel, l'homme "n'est pas naturellement immortel", et ne peut prétendre à "la vie éternelle», que si d'abord il y consent, et la veut. Cette réappropriation d'une "vérité » fondatrice du christianisme - occultée en Occident par des siècles de «culpabilisation » d'ouailles terrorisées par la pastorale de la peur et du péché, dont J. Delumeau a pu dire le bénéfice qu'en tirait l'Église -, ce retour aux sources, s'il ne propose pas une eau plus claire, du moins redistribue-t-il les données de problème soulevé. Au cœur de ce problème, la position du premier christianisme quant à l'immortalité. L'homme, écrit Fromaget, «n'est pas immortel en lui-même [...], il bénéficie de la faculté de disparaître, c'est-à-dire de mourir ». L'enfer est cette mort même. Par sa nature, l'homme est mortel. Nulle éternité, ici, mais une finitude absolue, « feu létal », « anéantissement pur et simple »; les « âmes damnées » y périssent en ce « feu superlatif, définitif, en plénitude ».

3 L'homme, ou la faculté du choix. Ceci intéresse l'anthropologue. Qui peut, la remettant dans son contexte de spiritualité où elle fut écrite, se rappeler cette définition de Théophile d'Antioche, que cite $\mathrm{M}$. Fromaget : « Ni complètement mortel, ni absolument immortel, l'homme capable des deux. " L'homme, pourrait-on dire aujourd'hui, maître de son "destin », traçant lui-même sa voie. Mais qu'en est-il alors de l'immortalité ? Elle n'est pas donnée d'emblée, comme constituant naturel de l'homme. L'immortalité, écrit Adalbert-Gautier Hamman - éminent spécialiste des écrits patristiques, et de saint Justin en particulier - "n'est pas au départ, mais à l'arrivée ». Dans le paysage contemporain, Claude Tresmontant note à son tour que, dans les perspectives juive et chrétienne, "l'immortalité de l'âme n'est pas un droit, une propriété de nature de l'âme. Elle est, elle sera, peut-être, un don ». Une grâce, à laquelle l'homme doit venir comme à sa chance ultime de "salut ». Pour aller au plus près des textes sacrés et de leur interprétation, loin d'être fondée en nature, l'immortalité est toujours sous condition. C'est à l'homme de décider, s'il aspire aux grâces de Dieu, ou s'il s'en détourne. Libre choix, qui ouvre, dans l'herméneutique du premier christianisme, un chapitre fondamental sur la situation de l'homme comme sujet. C'est sans doute à partir de cette irruption paradoxale de l'homme comme acteur décisif dans les Écritures et les commentaires qu'en ont proposé les "Pères évangélistes ", que de 
Hobbes à Bayle, de Diderot et Voltaire à Berdiaev, une libre pensée a pu se déployer, éteignant les derniers feux de l'enfer, et balayant la présomption de culpabilité naturelle de l'homme. Demeure l'immortalité, cette affaire privée entre soi-même et l'autre. L'Autre? 